\title{
Water, Electrolyte, and Endocrine Homeostasis in Infants with Bronchiolitis ${ }^{1}$
}

\author{
DAVID GOZAL, ANDREW A. COLIN, MICHAEL JAFFE, AND ZEEV HOCHBERG \\ Department of Pediatrics, Haifa Medical Center (Rothschild) [D.G., A.A.C., M.J.], and Division of Pediatric \\ Endocrinology, Rambam Medical Center [Z.H.] and Faculty of Medicine, Technion-Israel Institute of
}

Technology, Haifa, Israel

\begin{abstract}
Twenty-two of 23 consecutive infants with bronchiolitis, $5.5 \pm 3.5$ mo of age, showed a $1.9 \pm 1.4 \%$ increase in body weight, increased urinary osmolality of $737 \pm 193 \mathrm{mmol} / \mathrm{L}$ with low plasma osmolality of $275 \pm 4$ $\mathrm{mmol} / \mathrm{L}$, and markedly elevated plasma antidiuretic hormone (ADH) levels of $114 \pm 225 \mathrm{pg} / \mathrm{mL}$. Increased ADH, which usually suppresses plasma renin activity, was associated with increased plasma renin activity of 11-55 ng angiotensin $1 / \mathrm{mL} / \mathrm{h}$ (normal for age $<10 \mathrm{ng}$ angiotensin $1 /$ $\mathrm{mL} / \mathrm{h}$ ). Hyperaldosteronism was evident from the low fractional excretion of sodium of $0.27 \pm 0.2 \%$ and high fractional excretion of potassium of $21 \pm 15 \%$. Serum sodium concentrations were normal. All of the pathologic findings returned to normal when the bronchiolitis subsided. A control group of 10 infants with nonrespiratory febrile illness did not show any of the above abnormalities. Thus, bronchiolitis of infancy is characterized by both increased ADH secretion and hyperreninemia with secondary hyperaldosteronism, which induce water retention but counterbalance each other with respect to serum sodium. Increased ADH secretion as well as increased plasma renin activity are not "inappropriate," but rather suggest a response to the perception of hypovolemia by intrathoracic receptors. We therefore conclude that the clinical management of bronchiolitis requires close monitoring of body wt and plasma osmolality-urinary osmolality relationship; serum sodium levels may be misleading. (Pediatr Res 27: 204209, 1990)
\end{abstract}

\section{Abbreviations}

ADH, antidiuretic hormone

SIADH, syndrome of inappropriate ADH secretion

PRA, plasma renin activity

FE, fractional excretion

Uosm, urinary osmolality

Posm, plasma osmolality

Ang, angiotensin

It has been our clinical impression that infants with severe bronchiolitis develop facial puffiness that lessens and disappears as the respiratory distress improves. The possibility that excess fluid retention causes this appearance has been reinforced by the observation that concomittant with the loss of facial puffiness, a reduction in body wt occurs. The association of (SIADH) has

Received February 27, 1989; accepted September 25, 1989

Correspondence and reprint requests to Dr. D. Gozal, Dept. of Pediatrics, Haifa Medical Center, P.O.B. 4940, Haifa 31048, Israel.

${ }^{1}$ Presented at the American Thoracic Society Meetings, Cincinnati, OH 1989 and the 19th International Congress of Pediatrics, Paris, France 1989. been described in severe pulmonary conditions in childhood (19) including bronchiolitis $(4,8)$.

Our study was undertaken to evaluate whether the elevated $\mathrm{ADH}$ and plasma renin levels are a common finding in bronchiolitis and represent a response to a perceived diminished intravascular volume.

\section{MATERIALS AND METHODS}

The subjects included in the study were all children of younger than 12 mo old and weighing more than $3.5 \mathrm{~kg}$ admitted to the pediatric department over a 3-mo period (December 1986 through February 1987) with a clinical diagnosis of bronchiolitis. None of the patients had a history of preceding chronic disease or was receiving medication. Inasmuch as no precise definition of acute bronchiolitis has been agreed upon in the literature, the diagnosis was based on the following clinical features (10): a history of preceding upper respiratory tract infection with an acute onset of illness, mild fever, dyspnea, tachypnea, chest retractions, wheezing, rhonchi with or without rales and evidence of hyperinflation of the chest, both clinical and radiologic. No attempt to define the specific viral etiology of the disease was made. A diagnostic agreement of two pediatricians was required for the patient to be included in the study.

On admission each patient underwent the following protocol: A thorough medical history and physical examination. A clinical symptom grading system as described by Wennergren et al. (11) was repeated every $6 \mathrm{~h}$ to assess semiquantitatively the evolution of the disease in each patient. Laboratory investigations included the following: chest $\mathrm{x}$-ray, $\mathrm{CBC}$, arterial blood gases, serum electrolytes, urea and creatinine, and plasma osmolality, PRA, and ADH levels. Every $8 \mathrm{~h}$, wt was measured on an electronic scale, and urine was collected and analyzed for electrolytes, creatinine, and osmolality. All tests were repeated upon discharge. To ascertain that the abnormalities in fluid balance observed were indeed due to bronchiolitis and not to the stress of acute disease, 10 sick infants were examined for the same parameters listed above. These stressed control infants, age 3.5 $\pm 1.3 \mathrm{mo}$, had acute febrile disease with rectal temperature higher than $39.5^{\circ} \mathrm{C}$ without respiratory or gastrointestinal symptoms and no evidence of CNS infection. All the values from the control group were obtained on admission.

Oral fluid intake was unrestricted but in infants with marked respiratory distress and feeding difficulties intravenous fluids were administered. In these cases, a total of $100 \mathrm{~mL} / \mathrm{kg}$ of dextrose $5 \%$ in $\mathrm{NaCl} 0.33 \%$ was administered daily. Oxygen through a tent was added if needed, to maintain the arterial oxygen tension between 70 and 90 torr.

Plasma ADH levels were determined by the radioimmunoassay method of Husain et al. (12). Blood samples for ADH were collected in heparinized tubes on ice, centrifuged immediately at $-4^{\circ} \mathrm{C}$, separated, and stored frozen with $0.1 \%$ acetic acid. Ex- 
traction with acetone and delipidation of the extract with petroleum ether was performed and the samples were lyophilized and stored at $-20^{\circ} \mathrm{C}$ until assayed. Recovery was 65 to $70 \%$ and assay sensitivity was $0.1 \mathrm{pg} / \mathrm{mL}$ with an intraassay coefficient of variation of $16.7 \%$ and an interassay coefficient of variation of $17.2 \%$.

Plasma and urine osmolality were determined by freezing point depression using a Fiske OU osmometer that was calibrated daily with Accuref 300 . We obtained an intraassay variation of 0.5 to $0.7 \%(n=15)$, and the interassay variation was $0.3 \%$ (mean $280.1 \mathrm{mmol} / \mathrm{kg} ; n=36$ ).

Two $\mathrm{mL}$ of blood for PRA were collected in ice chilled plastic tubes containing $10 \mathrm{mg}$ EDTA. Plasma was immediately separated in a refrigerated centrifuge and kept stored at $-20^{\circ} \mathrm{C}$ until assay. PRA was determined by angiotensin 1 generation at $\mathrm{pH}$ 6.0 with EDTA, dimercaprol (BAL), and 8-hydroxiquinoline as inhibitors of converting enzyme and angiotensinase activity and results expressed in ng Ang $1 / \mathrm{mL} / \mathrm{h}$. New England Nuclear commercial kit (New England Nuclear, Boston, MA), RIANEN, was used for the RIA. Intraassay coefficients of variation for PRA at concentrations of $0.1,1.0,4.0 \mathrm{ng}$ Ang $1 / \mathrm{mL} / \mathrm{h}$ were 7 , 4 , and $8 \%$, respectively. Interassay values at $0.1,2.0$, and $4.0 \mathrm{ng}$ Ang $1 / \mathrm{mL} / \mathrm{h}$ concentrations were 10,7 , and $12 \%$. The normal range of values used for the population under study was 1.5 to $10 \mathrm{ng}$ Ang $1 / \mathrm{mL} / \mathrm{h}$, as recently published by Fiselier et al. (13).

Fractional excretions of sodium and potassium were calculated using the standard formula shown below:

$$
\text { FEsol }(\%)=\frac{U_{\text {sol }} * \text { Scr }}{\text { Ucr*Ssol }} * 100
$$

Where FEsol indicates fractional excretion of solute and $U$ and $S$ the respective concentrations of solute and creatinine (cr) in either urine or serum. The simultaneous urine and plasma osmolality value pairs obtained in each patient were plotted on a standard nomogram (14). Plasma osmolality values were also correlated to plasma ADH concentrations and analyzed graphically according to available published data (15-17). Parental informed consent was obtained in each case before inclusion in the study. Statistical analysis of the data was performed using the $t$-test for paired or nonpaired data as appropriate. Significance was indicated by $p \leq 0.05$.

\section{RESULTS}

Twenty-three patients, 16 boys and seven girls, comprised the cohort. Mean age was $5.5 \pm 3.5$ mo. The mean duration of symptoms before admission was $3.1 \pm 1.9$ days and that of dyspnea $1.5 \pm 0.9$ days. The mean dyspnea severity score on a scale of 0 to 6 was $3.65 \pm 0.95$ on admission. Arterial blood gases drawn on room air showed a mean $\mathrm{PO}_{2}$ of $71.3 \pm 12.2 \mathrm{~mm}$ $\mathrm{Hg}$ (range 48-94 mm Hg), mean $\mathrm{PCO}_{2} 36 \pm 6 \mathrm{~mm} \mathrm{Hg}(27-54)$, and mean pH $7.36 \pm 0.04$ (7.29-7.42). Chest $\mathrm{x}$-rays disclosed hyperinflation in all patients and small, usually unilateral infiltrates in six.

The relationship of urine osmolality to plasma osmolality, as depicted in Figure 1, shows that in 22 patients on admission, the Uosm-Posm values fell to the left of the nomogram lines. In all but four patients, Uosm-Posm values on discharge returned to within the nomogram lines. The mean Posm was $275.2 \pm 4.1$ mosm $/ \mathrm{L}$ on admission and $283.8 \pm 2.2 \mathrm{mosm} / \mathrm{L}$ on discharge $(p<0.001)$, compared to $284 \pm 1.1 \mathrm{mosm} / \mathrm{L}$ in the stressed control patients. Patients' Uosm admission and discharge values were $737 \pm 193 \mathrm{mosm} / \mathrm{L}$ and $396 \pm 184 \mathrm{mosm} / \mathrm{L}$, respectively $(p<0.001)$, compared to $444 \pm 131.7$ of the stressed controls.

Mean serum sodium levels were $136.8 \pm 2.8 \mathrm{mEq} / \mathrm{L}$ and 140.2 $\pm 2.1 \mathrm{mEq} / \mathrm{L}$ on admission and discharge, respectively $(p<$ 0.01 ), compared to $140.4 \pm 1.7 \mathrm{mEq} / \mathrm{L}$ of the stressed control group (Fig. 2). Hb, hematocrit, serum urea, and creatinine values did not change significantly in any of the patients during hospitalization.

Wt change calculated as the difference between wt on admission and at discharge divided by wt on admission and multiplied by 100 to be expressed as a percentage, showed a mean decrease of $1.9 \pm 1.4 \%$. In only two patients, a wt increase was noted.

The relationships of plasma ADH levels to osmolality on admission and discharge are shown in Figure 3. The respective mean ADH values are $113.8 \pm 224.8(n=23)$ and $1.9 \pm 0.9 \mathrm{pg} /$

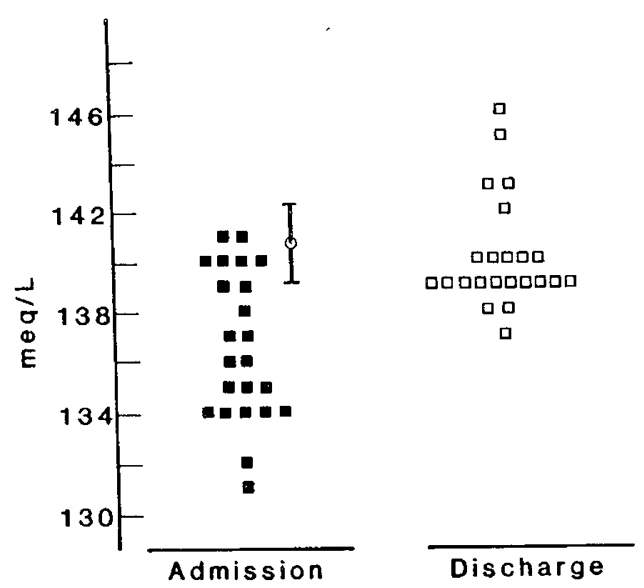

Fig. 2. Serum sodium levels in patients with bronchiolitis $(p<0.01)$. The mean \pm SD of the stressed control patients is indicated by the bar on the admission side.

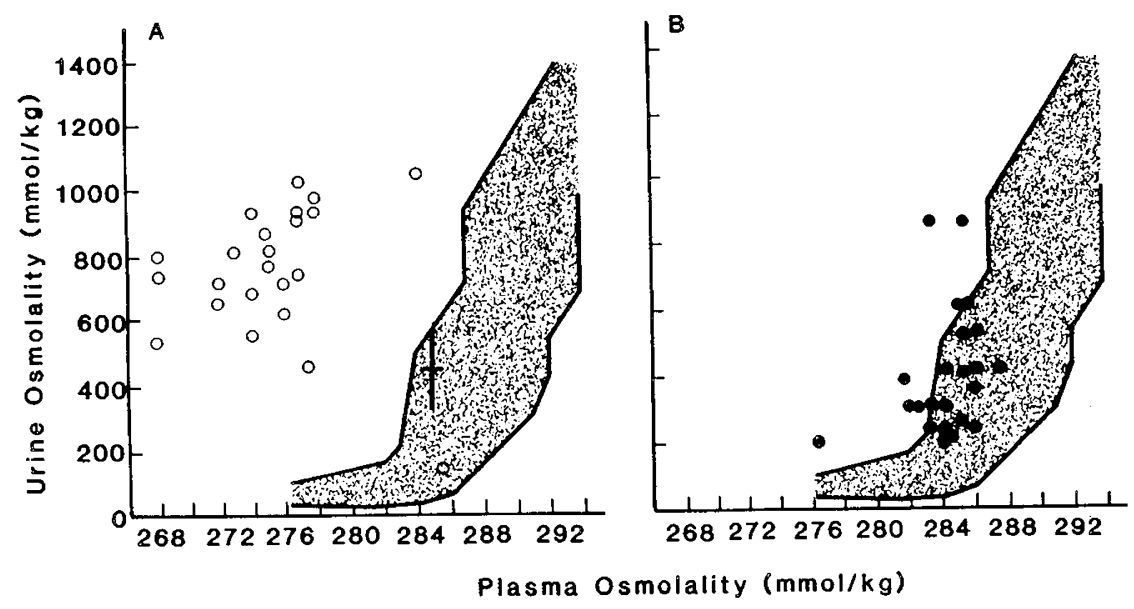

Fig. 1. Relationship of Uosm and Posm in 23 infants with bronchiolitis on admission (open circles) and discharge (closed circles) ( $p<0.001)$. The mean $\pm \mathrm{SD}$ of the stressed control patients is indicated by the cross in the shaded area of $A$. 
$\mathrm{mL}(n=15)(p<0.001)$. ADH values of the stressed control group were $1.0 \pm 1.3 \mathrm{pg} / \mathrm{mL}$. It was noteworthy that the only patient value within normal range on admission corresponded to the patient whose Uosm-Posm levels were within the nomogram lines in Figure 1.

Mean plasma renin activity levels on admission and discharge were $22.1 \pm 13.8$ and $9.1 \pm 3.8 \mathrm{ng}$ Ang $1 / \mathrm{mL} / \mathrm{h}$, respectively $(p$ $<0.025)$. The PRA values of the stressed control infants were $10 \pm 3.5$ Ang $1 / \mathrm{mL} / \mathrm{h}(p<0.0005$ compared to admission, $p>$ 0.05 compared to discharge) (Fig. 4). The mean FENa and FEK on admission were calculated as $0.27 \pm 0.2$ and $21.6 \pm 14.7 \%$, respectively. In all but four patients the FENa was found to be increased at discharge so that a mean value of $0.62 \pm 0.39 \%$ was obtained. A reciprocal decrease of FEK to $8 \pm 4.3 \%$ was found at discharge in all but two patients. The FENa/FEK ratios $(\times 10)$ increased therefore from $0.16 \pm 0.14$ to $0.86 \pm 0.52(p<0.001)$. FENa in the stress control infants was $0.43 \pm 0.18 \%$ (mean \pm $\mathrm{SD}$ ). FEK was $4.9 \pm 0.2 \%$. The mean ratio was $0.9 \pm 0.3$. Results of these admission fractional excretion values and their ratio in the control group were not statistically different from the discharge values of the bronchiolitis patients. The individual changes occurring in these parameters are shown in Figure 5.

Two illustrative cases are shown in Figure 6 that depict the concomitant changes observed throughout hospitalization in the clinical status, body wt, and urine osmolality.

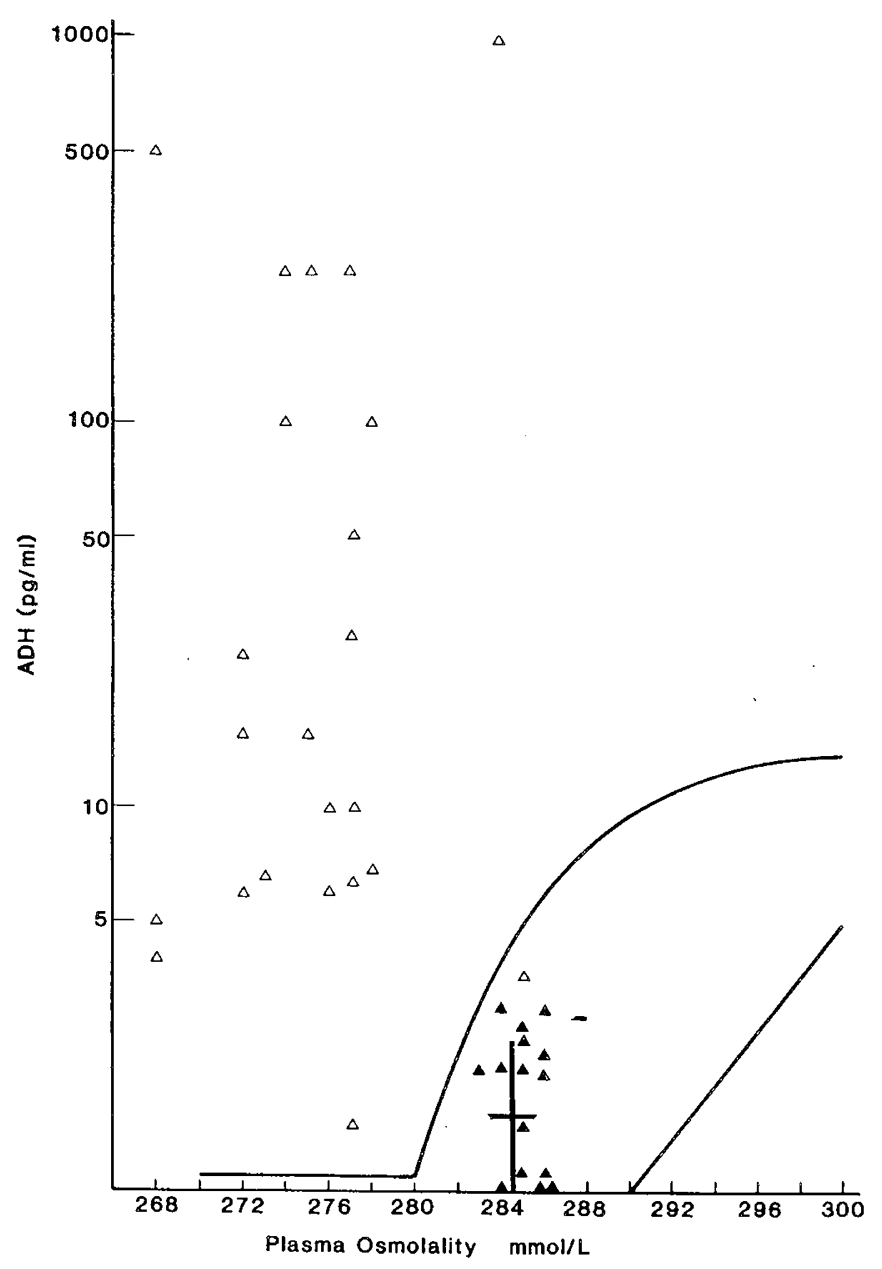

Fig. 3. Relationship of plasma ADH levels and plasma osmolality in infants with bronchiolitis on admission (open triangles) and discharge (closed triangles) $(p<0.001)$. The values for the stressed control infants are marked by the cross (mean $\pm \mathrm{SD}$ ).

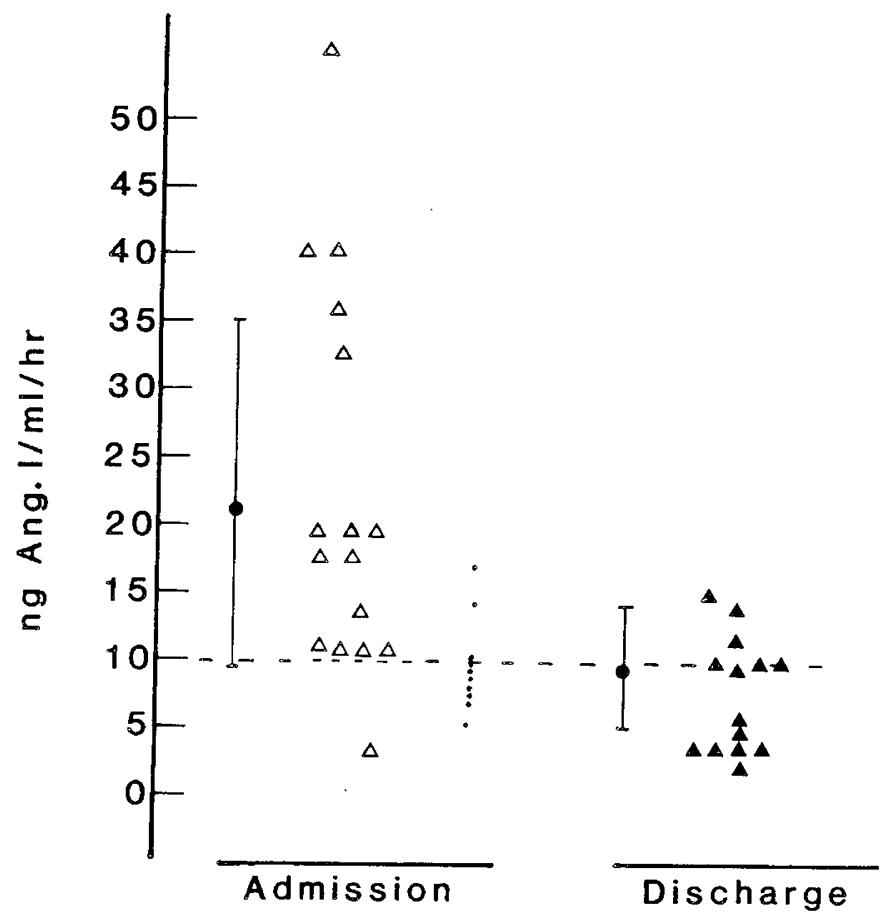

Fig. 4. PRA in patients with bronchiolitis $(p<0.025)$. The stressed control values are indicated as dots on the admission panel.

\section{DISCUSSION}

SIADH, as described by Schwartz et al. (18), implies in its classical clinical expression the presence of hyponatremia with continuing urinary sodium excretion, and inappropriately high urinary osmolality as related to plasma osmolality in the absence of renal or adrenal disease. The occurrence of SIADH in various pulmonary conditions including bronchiolitis, has been noted, and several pathophysiologic mechanisms may be involved (19). The incidence of SIADH, within a cohort of patients with bronchiolitis admitted consecutively during a seasonal epidemic, has not as yet been systematically studied. Our study was conducted to determine whether the perception of diminished intravascular volume during bronchiolitis is commonly associated with elevated plasma vasopressin and renin levels rather than incidental SIADH, as would be suggested by the occasional case reports in the literature $(4,8)$.

To evaluate this assumption, we used adult Posm-Uosm nomograms previously validated by us in infants and children (19) but not in newborns and premature infants (20). The high urine osmolality in the presence of low plasma osmolality observed on admission in all but one patient, together with the wt decrease observed on discharge in 21 of 23 patients, appear to confirm our hypothesis, as do the concomitant high ADH levels which revert to normal values on discharge (Fig. 3).

Our study group of infants, having recovered from bronchiolitis, had lower mean ADH levels than those in Rascher's study (21). This disparity cannot be explained exclusively on the grounds of different study populations or assay methods used. Further studies in this age group are needed to establish reliable reference values. Three mechanisms could have played a role in the causation of increased ADH observed in our patients. First, a vagal reflex stimulated by atrial baroreceptors triggered by decreased venous return. This is caused by the increased intrathoracic pressure associated with the increased work of breathing in bronchiolitis $(22,23)$. Hyperinflation caused by air trapping may, through the same mechanism, stimulate a similar ADH response (24). The second possible mechanism is hypoxemia, 


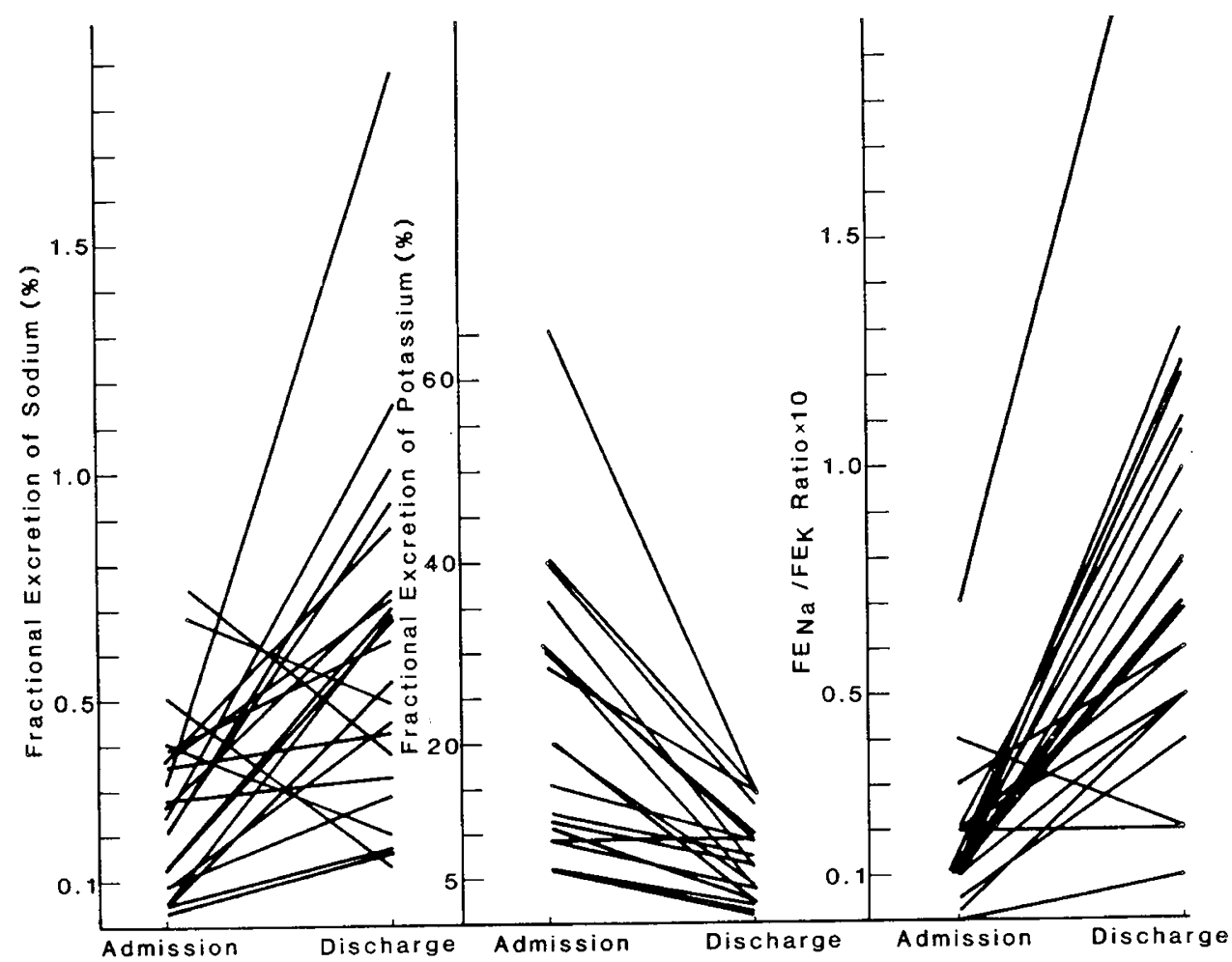

Fig. 5. Individual fractional excretions of FENa, FEK, and their ratio in infants with bronchiolitis. In the 10 stressed control infants FENa was $0.43 \pm 0.18 \%$ (mean $\pm \mathrm{SD}$ ), FEK was $4.9 \pm 0.2 \%$ and mean ratio $0.9 \pm 0.3$.
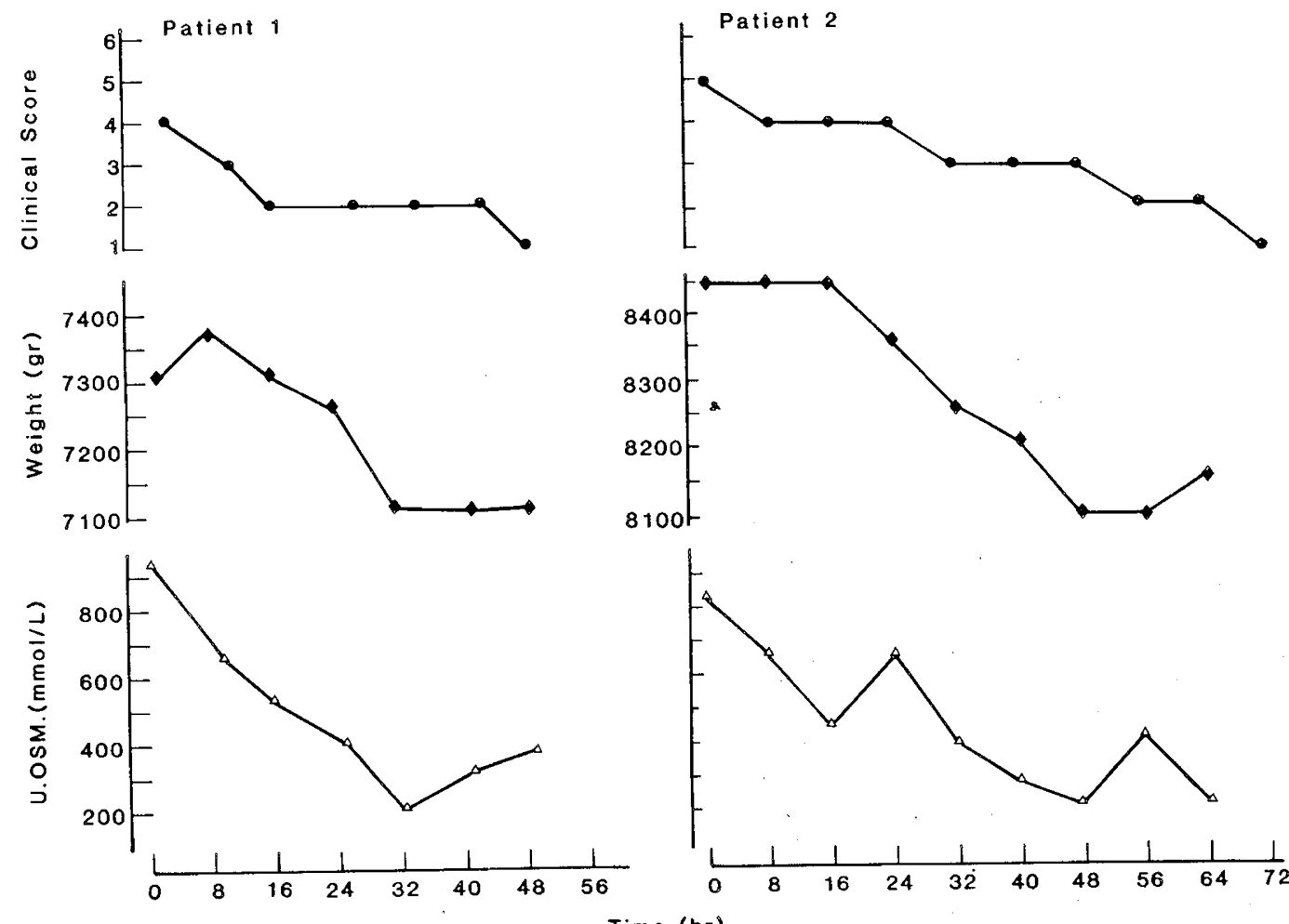

Fig. 6. Flow diagram of two illustrative cases of bronchiolitis with respect to clinical severity of respiratory distress, weight, and urinary osmolality.

which has been independently shown to induce ADH secretion $(25-27)$. Finally, stress through central hypothalamic pathways may also play a role $(23,28)$. This latter mechanism may have been excluded by our findings in the control infants whose admission values were all comparable to the bronchiolitis group discharge values. it is, however, possible that the type or degree of stress caused by high fever may not be comparable to that associated with bronchiolitis. 
PRA levels are expected to be low in the presence of high ADH because of increased plasma volume (29-32) and a direct inhibitory effect of ADH on renin secretion (33). The association of elevated PRA levels in patients with increased ADH seems to occur specifically in conditions resulting from increased intrathoracic pressure. The physiologic mechanisms by which PRA is elevated in bronchiolitis involve vagal reflexes similar to those described for ADH release in this clinical setting, i.e., decreased venous return triggering atrial baroreceptors with ensuing stimulation of juxtaglomerular renin secretion through sympathetic pathways (32) and stress-associated PRA elevation $(34,35)$.

This hyperreninemia resulted in secondary hyperaldosteronism as evidenced by sodium retention (decreased FENa) and concomitant potassium diuresis (elevated FEK) as shown in Figure 5. This in turn could have contributed to further water retention and increase in the patients' body wt. The results of our study demonstrate two mechanisms operative in water retention in infants with bronchiolitis, i.e., increased ADH and hyperreninemia and consequent hyperaldosteronism.

The recent observations by Dreyfus et al. (36), showing a marked decrease in free water clearance coincidental with increased plasma vasopressin in infectious pneumonia, probably reflect the same mechanisms, although PRA was not examined in their study.

Schwartz's original description of the syndrome of inappropriate $\mathrm{ADH}$ secretion requires that patients have an elevated urinary sodium excretion, or a normal or elevated fractional excretion of sodium as well as hyponatremia. Both of these findings were absent in our patients.

We hypothesize that the attempt to conserve salt and water is in fact appropriate to the clinical situation in which there is a perception, albeit erroneous, of hypovolemia. This in turn leads to activation of the mechanisms necessary to maintain volume. Thus, in the face of nonosmotic stimuli to vasopressin release in which there is activation of volume sensors, the urine will appear to be inappropriately concentrated but is consistent with the more pressing need to preserve intravascular volume. This is further buttressed by the finding of a parallel rise of PRA.

The concordant and similar directions in the change of vasopressin and plasma renin activity underscore the appropriate physiologic response demonstrated by the body to the perception that intravascular volume is contracted in lung disease involved with increased intrathoracic pressure. These two mechanisms have a masking effect on the serum sodium by virtue of their opposite influence on these levels. In SIADH, water retention and continuing natriuresis result in hyponatremia. In patients with bronchiolitis this seems to be counterbalanced by the hyperreninemic-hyperaldosteronism state inducing sodium retention. We assume that the relatively well-preserved serum sodium concentrations found in this elevated ADH setting were due to the accompanying secondary hyperaldosteronism.

Whether the dual response of $\mathrm{ADH}$ and PRA increase in bronchiolitis has any beneficial impact on the child with pulmonary disease, could perhaps be elucidated by studies in which vasopressin antagonists are administered in a similar clinical setting and noting the effect on the clinical course of the disease.

The possible effect of ANF was not investigated. The decreased filling of the right atrium caused by increased intrathoracic pressure and a resulting inhibition of ANF, may also have played a role in the sodium and fluid homeostasis of these patients.

In the management of infants with bronchiolitis the clinician may be misled by the normal serum sodium, but should be aware of the possibility of pending fluid overload. With this in mind, fluid intake should be carefully adjusted to the individual patient with this complex clinical condition, using the Uosm-Posm relationship together with close monitoring of body wt.

The observation by Tal et al. (37) showing that corticosteroid therapy had a beneficial effect on their bronchiolitis patients requires further investigation. Bearing in mind the fluid retention caused by both increased $\mathrm{ADH}$ and renin activity described by us, we share the reservations regarding use of corticosteroids in bronchiolitis in Skoner and Caliguri's recent review (38), and believe that caution should be exercised when using these fluid retaining hormones in this disease.

\section{REFERENCES}

1. Darrow DC, Hartmann AF 1929 Chemical changes occurring in the body as a result of certain diseases. IV. Primary pneumonia in children. Am $\mathbf{J}$ Dis Child 37:323-334

2. Mor J, Ben Galim E, Abrahamov A 1975 Inappropriate antidiuretic hormone secretion in an infant with severe pneumonia.Am J Dis Child 129:133-135

3. Paxson CL, Stoerner JW, Denson SE, Adcock EW, Morriss Jr FH 1977 Syndrome of inappropriate antidiuretic hormone secretion in neonates with pneumothorax or atelectasis. J Pediatr 91:459-463

4. Rivers RPA, Forsling ML, Olver RP 1981 Inappropriate secretion of antidiuretic hormone in infants with respiratory infections. Arch Dis Child 56:358363

5. Singleton R, Moel DI, Cohn RA 1986 Preliminary observation of impaired water excretion in treated status asthmaticus. Am J Dis Child 140:59-61

6. Rao M, Eid N, Herrod L, Parekh A, Steiner P 1986 Antidiuretic hormone response in children with bronchopulmonary dysplasia during episodes of acute respiratory distress. Am J Dis Child 140:825-828

7. Cohen LF, di Sant'Agnese PA, Taylor A, Gill Jr JR 1977 The syndrome of inappropriate antidiuretic hormone secretion as a cause of hyponatremia in cystic fibrosis. J Pediatr 90:574-578

8. Le Moing G, Gendrell D, Couvreur J, Gaultier CI, Tournier G, Gerbeaux J 1977 Secretion inappropriee d'hormone antidiuretique au cours des infections respiratoires aigues a adenovirus chez l'enfant. Nouv Press Med 6:38253833

9. Hazinski TA, Bablock WA, Engelhardt B 1988 Control of water balance in infants with bronchopulmonary dysplasia: role of endogenous vasopressin. Pediatr Res 23:86-88

10. Wohl MEB, Chernick V 1978 Bronchiolitis. Am Rev Respir Dis 118:759-781

11. Wennergren G, Engstom I, Bjure J 1986 Transcutaneous oxygen and carbon dioxide levels and a clinical symptom scale for monitoring the acute asthmatic state in infants and young children. Acta Pediatr Scand 75:465-469

12. Husain MK, Fernando N, Shapiro M, Kagan A, Glick SM 1973 Radioimmunoassay of arginine vasopressin in human plasma. J Clin Endocrinol Metab 37:616-625

13. Fiselier T, Monnens L, van Munster P, Jansen M, Peer P, Rijnen P 1984 The renin-angiotensin-aldosterone system in infancy and childhood in basal conditions and after stimulation. Eur J Pediatr 143:18-24

14. Streeten DHP, Moses AM, Miller M 1987 Disorders of the neurohypophysis. In: Harrison's Principles of Internal Medicine. 11 th ed. McGraw Hill, New York, pp 1722-1732

15. Robertson GL, Mahr EA, Athar S, Sinha T 1973 Development and clinical application of a new method for the radioimmunoassay of arginine vasopressin in human plasma. J Clin Invest 52:2340-2352

16. Robertson GL, Shelton RL, Athar S 1976 The osmoregulation of vasopressin. Kidney Int 10:25-37

17. Bevilacqua M, Meroni R, Dagani R, Renesto E, Baruto C, Norbiato G 1985 Role of blood osmolality in the regulation of vasopressin secretion in man: application of a new radioimmunoassay method for vasopressin. $\mathbf{J}$ Endocrinol Invest 8:97-101

18. Shwartz WB, Bennet W, Curelop S, Bartter FC 1959 A syndrome of renal sodium loss and hyponatremia probably resulting from inappropriate secretion of antidiuretic hormone. Am J Med 23:529

19. Richman RA, Post EM, Notman DD, Hochberg Z, Moses AM 1981 Simplifying the diagnosis of diabetes insipidus in children. Am J Dis Child 135:839841

20. Sujov P, Kellerman L, Zeltzer M, Hochberg Z 1984 Plasma and urine osmolality in fullterm and preterm infants. Acta Pediatr Scand 73:722-726

21. Rascher W, Rauh W, Brandeis WE, Huber KH, Scharer K 1986 Determinants of plasma arginine-vasopressin in children. Acta Pediatr Scand 75:111-117

22. Stokes GM, Milner AD, Groggins RC 1981 Work of breathing, intrathoracic pressure and clinical findings in a group of babies with bronchiolitis. Acta Pediatr Scand 70:689-694

23. Schrier RW, Berl T, Anderson RJ 1979 Osmotic and non osmotic control of release. Am J Physiol 236:F321-332

24. Rao M, Eid N, Mitchell M, Steiner P 1985 Hyperinflation (airtrapping) as a stimulant of ADH response in children with chronic asthma. Am Rev Respir Dis 131(suppl):A263

25. Anderson RJ, Pluss RG, Beins AS, Jackson JT, Arnold PE, Schrier RW, McDonald KM 1978 Mechanism of effect of hypoxia on renal water excretion. J Clin Invest 62:769-777

26. Forsling ML, Ullman E 1974 Release of vasopressin during hypoxia. J Physiol 241:35-46

27. Wang BC, Share L, Goetz KL 1985 Factors influencing the secretion of vasopressin in cerebrospinal fluid. Fed Proc 44:72-77

28. Bonjour JP, Malvin RL 1970 Plasma concentration of $\mathrm{ADH}$ in conscious and anesthetised dogs. Am J Physiol 218:1128-1132

29. Fichman MR, Michelakis AM, Hoprton R 1974 Regulation of aldosterone in 
the syndrome of inappropriate antidiuretic hormone secretion (SIADH). J Clin Endocrinol Metab 39:136-144

30. Joppich R Weber P 1976 Effects of $\mathrm{ADH}$ on the activity and function of renin-angiotensin-aldosterone system in infants and children. Eur J Pediatr 122:303-308

31. Annat G, Grandjean B, Vincent M, Jarsaillon E, Sassard J 1976 Effects of right atrial stretch on plasma renin activity. Arch Int Physiol Biochem $84 \cdot 311-315$

32. Keeton TK, Campbell WB 1980 The pharmacologic alteration of renin release. Pharmacol Rev 32:81-227

33. Hesse B, Nielsen I 1977 Supression of plasma renin activity by intravenous infusion of antidiuretic hormone in man. Clin Sci Mol Med 52:357-360

34. Johnson MD, Fahri ER, Troen BR, Barger AC 1979 Plasma epinephrine and control of plasma renin activity: possible extrarenal mechanisms. Am J Physiol 236:H854-859

35. Johnson MD, Shier DN, Barger AC 1979 Circulating catecholamines and control of plasma renin activity in conscious dogs. Am J Physiol 236:H463470

36. Dreyfuss D, Leviel F, Paillard M, Rahmani J, Coste F 1988 Acute infectious pneumonia is accompanied by a latent vasopressin-dependent impairment of renal water excretion. Am Rev Respir Dis 138:583-589

37. Tal A, Bavilski C, Yohai D, Bearman JE, Gorodischer R, Moses SW 1983 Dexamethasone and salbutamol in the treatment of acute wheezing in infants. Pediatrics 71:13-18

38. Skoner D, Caliguiri L 1988 The wheezing infant. Pediatr Clin North Am 35:1011-1030

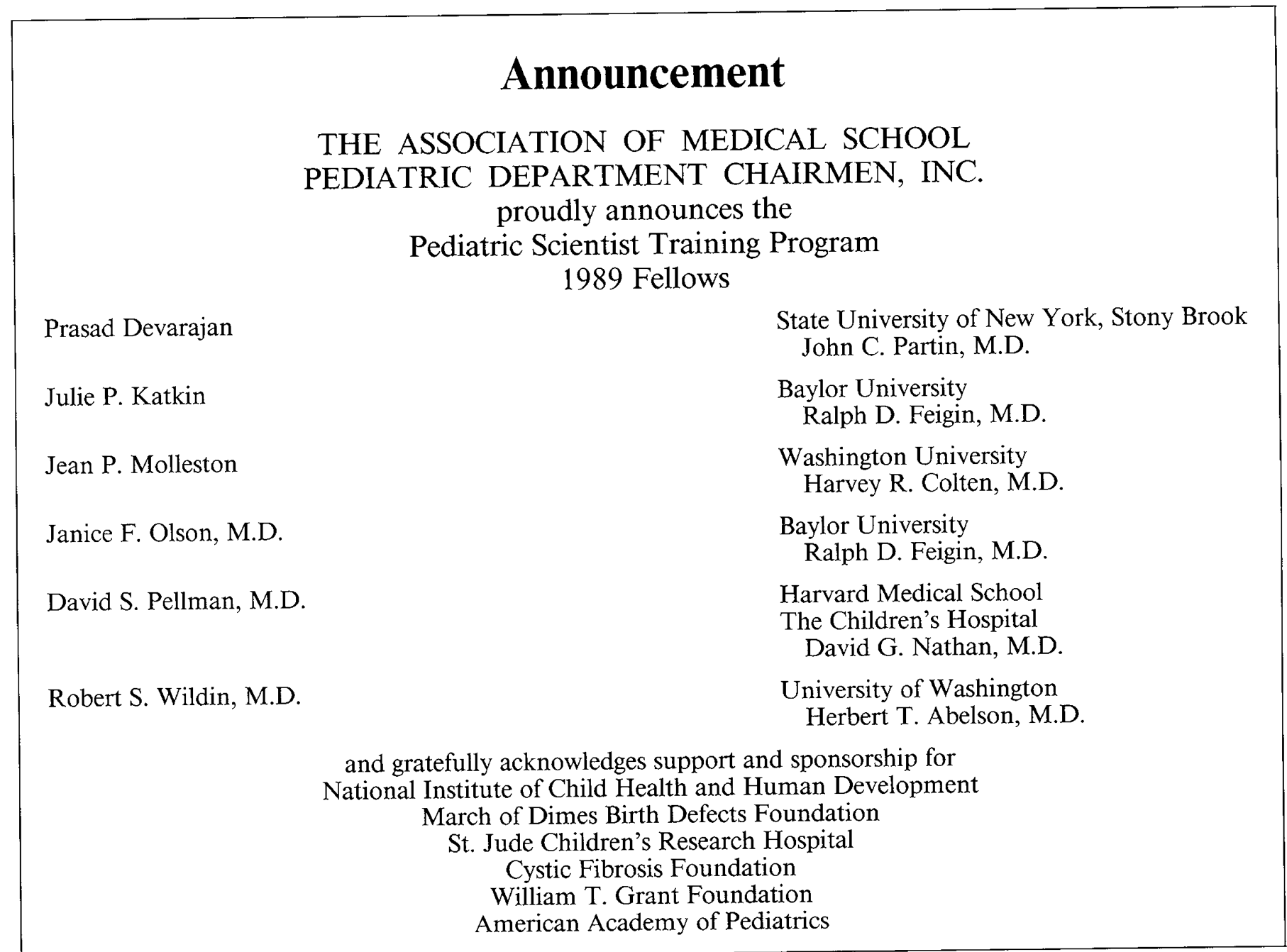

